\title{
Developing the Business Process \\ Management Performance \\ of an Information System Using the Delphi Study Technique
}

\author{
Hisham AbouGrad, Jon Warwick, and Amare Desta
}

\section{Introduction}

Developing high quality decision-making processes are major elements of an organisation's business process systems success. Accordingly, appropriate decisionmaking business practice techniques are required to ensure that business process systems perform to high standards. The Delphi study technique is well-known for exploring organisational issues and helping to develop a business decision-making process. The Delphi study technique was first developed as a communication control technique for forecasting based on a panel of experts [1, 2]. Nowadays, the Delphi study technique is also used as a method for resolving important business process management (BPM) issues, make predictions, and develop decision-making indicators for decision-makers who look to improve their workflow systems policy, procedures, or quality assurance [3].

Business process management is a business management approach that concentrates on studying business process systems with the aim of improving business performance based on improved effectiveness and efficiency levels. BPM systems have mainly looked to improve the efficiency of workflow systems by enhancing the role of information systems. Thus, BPM systems have evolved to be a new business management approach for forecasting business technical requirements to optimise workflow systems. BPM approaches are used to find out about business process (workflow) systems effectiveness and efficiency using business practices and studies to successfully achieve the business objectives [4].

Information systems (IS) are the main component of business development and innovation that aim to improve business profit and return levels [5]. Information

H. AbouGrad $(\bowtie) \cdot$ J. Warwick $\cdot$ A. Desta

School of Business, London South Bank University, London, UK

e-mail: abougrah@1sbu.ac.uk; warwick@1sbu.ac.uk; destaa@1sbu.ac.uk 
systems have three key elements, which are employees (people), responsibilities (tasks), and technology [6]. The business process operates through an IS model that contains the BPM framework for the organisation's business operations and activities.

The Delphi method can be used to enhance the validity of a BPM framework as it produces results with high validity when compared to other data collection procedures. In fact, the Delphi method has resulted in a higher number of insights compared to other decision-making methods [7]. Hence, to develop information systems performance, an iterative study method is required to ensure the validity of BPM framework operations and activities. The Delphi method can be used to conceptualise and analyse the elements of an organisation's business process performance [8]. Thus, the Delphi method rounds can develop a decision-making instrument, which can be used as a model to improve a BPM framework for developing business information systems performance.

This paper looks at different Delphi and BPM research studies to confirm the usability of the Delphi method for developing business information systems by evaluating and improving business process systems performance. The paper presents a literature review where business process management and the Delphi study technique have been discussed in relation to business performance and information systems, and then the Delphi method details have been presented including Delphi's rounds (Table 1). Thereafter, the application of the Delphi method is discussed in relation to several published Delphi studies and supported by the empirical evidence reported in these studies. The paper then concludes by discussing Delphi's use in evaluating and developing business information systems performance.

Table 1 The Delphi method rounds

\begin{tabular}{|c|c|c|}
\hline Round & Input of the codification panel & Output of the expert panel \\
\hline 1 & $\begin{array}{l}\text { Brainstorming } \\
\text { - Identify indicators/factors } \\
\text { - Initial list of criteria }\end{array}$ & $\begin{array}{l}\text { - Initial criterion: } \\
\text { - Rate its importance } \\
\text { - Make open comments } \\
\text { - For the criteria: } \\
\text { - Rate overall importance } \\
\text { - Make open comments } \\
\text { - Propose missing criteria }\end{array}$ \\
\hline 2 & $\begin{array}{l}\text { Narrowing down } \\
\text { - Consolidate criteria }\end{array}$ & $\begin{array}{l}\text { - Per criterion: } \\
\text { - Rate its importance } \\
\text { - Give open comments } \\
\text { - For all criteria: } \\
\text { - Rate overall importance } \\
\text { - Give open comments }\end{array}$ \\
\hline 3 & $\begin{array}{l}\text { Weighing } \\
\text { - Determine final criteria } \\
\text { - Request weightings }\end{array}$ & $\begin{array}{l}\text { - For all criteria: } \\
\text { - Rate overall importance } \\
\text { - Give open comments } \\
\text { - Weigh criteria and options }\end{array}$ \\
\hline
\end{tabular}




\section{Literature Review}

\subsection{Business Process Management Evaluation}

BPM is a complete business management approach that focuses on the organisation's processes without looking at the organisation's functions [8]. BPM has been developed when investment in enterprise information systems have been made that aim to transfer non-information technology business processes to systemic information technology (IT) business processes [9].

The Delphi method has been used as a business study technique to produce empirical evidence supporting decision-making in several BPM situations [9]. An example is in studying BPM job descriptions, categories, technical skills, and systems experience and ability to find the ideal profiles and types of BPM professionals. Another example is in developing BPM project aims, objectives, phases, terms and conditions, and contractors' portfolio by BPM experts based on specific industries and locations. In fact, BPM is growing as a process-oriented management research field within the information systems area of research [4]. Also, BPM is recognised as an interdisciplinary approach to organisational business processes analysis, design, implementation, and improvement, as well as supporting the sustainability of information systems [9]. Thus, to evaluate the BPM mechanism for an organisation's information system effectiveness and efficiency, a methodology such as Delphi is essential to enable an evaluation process.

The Delphi method can be used to formulate key indicators to evaluate the organisation's BPM through factor analysis criteria such as variance inflation factor (VIF) and critical success factors (CSF) where an organisation can identify the BPM success and ensure sustainable implementation of the organisational BPM systems $[4,10]$.

\subsection{The Delphi Method and Business Process Management}

The Delphi method has been used to identify BPM success values by developing controlled decision-making criteria that aim to find consensus among a panel regarding BPM systems. The Delphi method is operationalised by setting sets of questions to a group of selected experts. The Delphi study questions are designed based on the use of questionnaires or interviews as data collection procedures. The Delphi study data collection procedures are used to improve the effectiveness and efficiency levels of an organisation BPM system [4].

A global Delphi study has recommended that the Delphi and BPM methods can be used to design and develop an organisation's BPM system components [4]. This study has recognised the use of BPM values in achieving BPM success. Hence, BPM values can be used along with the Delphi method to evaluate BPM systems performance. 
In fact, BPM approaches aim to improve an organisation's operational effectiveness and efficiency using BPM systems core values rather than an organisation's functional components [9]. For example, an improvement could be achieved by developing an organisation's product quality and customer services compliance.

\subsection{The Business Information System Performance}

Business information system performance is based on an organisation's business processes. Accordingly, when an organisation has established a BPM workflow system, the organisation decision-makers who are responsible for making decisions need an accurate business performance evaluation process to improve the business processes and information system performance, as well as ensure sustainable growth [11]. An organisation's decision-makers want a method that can help them understand BPM success values, so they can decide which business processes need improvement and what exactly should be done to boost business information systems performance.

Information systems are used to understand an organisation's information flow and solve business issues using BPM framework [12, 13]. Information systems and BPM frameworks together build the organisation's workflow information system (WIS).

In fact, WIS combines information systems software and hardware applications to achieve employees' daily tasks through automated business processes [13].

The Delphi method is a business practice methodology that uses expert feedback about business process information systems, so that decision-makers can develop and improve their organisation's business performance. This requires an appropriate WIS to ensure that the organisation has the right systematic business actions, and the Delphi method can enhance the understanding of the key efficient and effective business process factors to achieve the best business performance. In fact, WIS is a complete systematic solution that manages workflow technologies for information systems development and management [13]. Systematically, WIS allows the information system to achieve the required business performance. WIS needs business process management as a means of understanding business process efficiency and effectiveness by focusing on BPM values within the workflow of an information system implementation $[4,13]$.

\subsection{The Delphi Method and Information Systems}

To ensure the efficiency and effectiveness of an information system, the Delphi method as an iterative methodology has been shown to enhance the validity of the collected feedback data [7]. Results from applications of the Delphi method have included highly successful and innovative decision-making. In fact, Delphi as 
a decision support method results in a higher quality and quantity of decisions in comparison to other methods [7]. In general, reported business practice studies on information systems using the Delphi method are growing, and more BPM, WIS and business performance studies are emerging that suggest using Delphi to optimise business practices.

Business process management and workflow information systems join to form an organisation's systematic and automatic business process procedures. These deliver the services and products with the required levels of quality to ensure organisational business sustainability. Information systems are the engine of the organisation's complete workflow system, which is based on the organisation's BPM full lifecycle. An organisation's BPM is designed to understand business process efficiency and effectiveness using BPM organisational business values, which are used within the workflow process of an information system implementation [2, 4, 7]. On the other hand, the Delphi study technique can utilise BPM values as comprehensive key indicators to evaluate workflow information systems performance. Also, the Delphi method can discover business performance key issues and indicators by weighing decision criteria using its multistage decision-making steps to reach the right decisions (Table 1). We now discuss the Delphi method in more detail.

\section{Methodology}

\subsection{The Delphi Method Context}

The Delphi method was initially developed as a study technique for a project that utilised feedback from a panel of experts. The first project was named "Project DELPHI" at The RAND Corporation [1]. The Delphi study technique as a business practice method can be achieved by collecting expert opinions and identifying consensus positions using a process of controlled and structured feedback within different staged rounds fully utilising the experts' business experience [9]. There are several ways to use Delphi, for example some research studies depend on the experts for finding issues and key indicators while others make use of a literature review to formulate a set of indicators prior to the Delphi rounds [2, 4, 7].

The Delphi method has three basic rounds where each Delphi study round has a different purpose and aims [2]. The basic Delphi study rounds are Brainstorming, Narrowing down and Weighing. Table 1 summarises the conventional Delphi method rounds and their inputs and outputs [7].

\section{Brainstorming}

Delphi's Round 1 is Brainstorming, which is used to identify or select key indicators or factors and set up an initial list of criteria for decision-making. Brainstorming is 
usually implemented as an initial study for collecting a slice of the study data to propose the initial list of criteria and important key indicators. The Brainstorming round identifies the initial decision criteria, which will be the subject of Narrowing down in the second Delphi round $[2,7]$.

\section{Narrowing Down}

Delphi's Round 2 is Narrowing down, which narrows down the initial list of criteria in order to validate the factors or key indicators, and then rate or rank them based on their importance or feasibility. The narrowing down round validates the results from Delphi's first round (Brainstorming) and searches for a complete ratio, rating, or ranking to recognise the key indicators by measuring their importance or feasibility, with a degree of consensus obtained. This Delphi round produces a list of factors or key indicators to use in the Weighing, Delphi's third round [2, 7]. Moreover, the narrowing down confirms the key indicators of the business process system, which are used to evaluate an information system. This evaluation process identifies the business information systems key variables from the BPM values, and then rates the degree of consensus of each key variable. The narrowing down round results in both the recognised business information systems key variables and the rate of the consensus of each key variable, which will be used in Delphi's Weighting round $[4,8]$.

\section{Weighing}

Delphi's Round 3 is Weighing, which is used to weigh the rated indicators to reach consensus or verify the decision and present the Delphi study results. The weighing round is used to conduct the final evaluation to reach the Delphi study final answers and findings, so then the Delphi study results can be published. Thus, the study will determine the final criteria; an example is developing a weighting system for a workflow information system model [2]. The weighing round seeks the most reliable and valid business process key indicator variables of BPM values to obtain the best business performance. These key indicator variables of BPM values are an information system running principles that determine business process system structure and behaviour in the workflow information system [4, 8].

\subsection{Delphi Validity}

The Delphi method has been used to identify, select, conceptualise, and validate business process factors in many business studies (see for example [2]). Also, the Delphi method has been used to examine business process systems validity in the weighing final round through a quantitative evaluation of the validity of the workflow information system model. Thus, we believe that the Delphi method as an 
expert analysis methodology is appropriate as a basis for an organisational study to evaluate business process systems. The Delphi method results in quantitative measurement instruments that can be used to define specific business process system operations using BPM values multi-dimensional construction [4]. This gives empirical insights on the descriptive and predictive rule of the new business workflow information system model.

In fact, the Delphi method has a key methodological role that ensures the validity of Delphi results as experts can be asked to validate their results in the context of the final business process management study findings [2, 8]. The Delphi method rounds are procedures to ensure the decision quality and Delphi acts as a quality control and assurance strategy for enhancing the quality of an organisation's business decisions.

\subsection{Delphi Toward the Right Business Process Management Performance}

The Delphi method is used to produce appropriate decision factors for evaluating business workflow information systems. In parallel, BPM is an approach to improving process quality; for example, total quality management (TQM) aims to provide high quality products and services. Indeed, as we have argued BPM increases organisational efficiency and effectiveness through improvement and innovation using the Delphi method as a development concept that produces a set of indicators [4]. Thus, BPM values and Delphi study technique can be used to ensure the quality of the business process performance using Delphi's decision-making rounds and BPM key business quality factors, indicators, or values.

Information systems are used to improve business performance and individual's excellence by formulating BPM values as a BPM solution to develop the business environment $[4,8,13]$. Workflow is a BPM technology, which is used to deliver business performance requirements in order to achieve the business objectives. Workflow and information systems formulate workflow information systems, which are important for the organisation business development. WIS is a way to improve business performance, automate BPM, cut business costs, and manage BPM time. In fact, WIS is a complete systematic application to solve business process issues, as its key characteristic is to automate the business processes by linking staff tasks to IT systems [13].

Practically, WIS needs BPM values to understand an organisation's business processes and systems mechanism in order to automate them successfully. Thus, WIS strategic techniques are used to evaluate business information systems performance as WIS has an influence on running the business environment [4, 8]. The combination of WIS, BPM values and Delphi method enables an organisation to identify the right business decisions and have the advantage of identifying the performance indicators using BPM values and the Delphi method leading to the right business performance levels. 


\section{Application and Discussion}

There have been a number of studies published which have discussed the empirical results obtained by the use of Delphi method. These Delphi studies focus on finding consensus and determining the effectiveness of the criteria for measuring business activities and rules [3]. In addition, the Delphi method has generated effects on different business performance components, which impact on business processes efficiency and effectiveness. In this section, we discuss some elements of published Delphi studies and their results with the effects of Delphi and BPM values on business performance.

\subsection{The Delphi Method and Business Process Management Values}

Business process management values are the core values of the key indicators, which are recognised through a Delphi study to measure an organisation's workflow systems $[4,8]$. The recognised key indicators are the workflow information system driving factors; these factors are an instrument to quantitatively measure the workflow systems achievement of BPM objectives and of optimising business performance. Results from the Schmiedel et al. [8] global Delphi study have revealed key BPM core values. This study has identified four BPM core values (Table 2) which are Customer orientation (C), Excellence (E), Responsibility (R) and Teamwork (T). The BPM core CERT values have sub-indicators, which are used as key indicators to measure the workflow system. For example, the BPM value 'Excellence' has the following key indicators: Continuous improvement, Innovation, Leanness, and Quality; these indicators as described in Table 2 could

Table 2 The Delphi study identified BPM values [8]

\begin{tabular}{|c|c|c|}
\hline BPM core values & Key indicators (variables) & Description \\
\hline Customer orientation & Customer orientation & $\begin{array}{l}\text { The business driver and target of the } \\
\text { workflow system }\end{array}$ \\
\hline \multirow[t]{4}{*}{ Excellence } & Continuous improvement & $\begin{array}{l}\text { The process to satisfy business and } \\
\text { customer needs }\end{array}$ \\
\hline & Innovation & $\begin{array}{l}\text { The business processes creativity and } \\
\text { upgrade }\end{array}$ \\
\hline & Leanness & The business processes efficiency \\
\hline & Quality & $\begin{array}{l}\text { The ideal and right business processes } \\
\text { performance }\end{array}$ \\
\hline Responsibility & Responsibility & $\begin{array}{l}\text { The workflow commitment, } \\
\text { engagement, and mission }\end{array}$ \\
\hline Teamwork & Cross-functional orientation & $\begin{array}{l}\text { The workflow system non-functional } \\
\text { elements }\end{array}$ \\
\hline
\end{tabular}


be evaluated to produce the workflow system excellence rate (percentage). If the excellence rate is found to be low, then the organisation can use the excellence value to improve the workflow performance by focusing on the business excellence key indicators (variables). Therefore, workflow systems characteristics can be examined to evaluate the business processes in order to have more efficient and effective business performance. Also, the Delphi method and BPM values can be used to have a systematic BPM construct as a concept in the first stage of the decisionmaking process until completion of the concept test stage, and then the concept can be implemented as a complete BPM system for the organisation.

\subsection{Results From Delphi Method}

The application of the Delphi method has resulted in publication of important and valuable research studies and results, which lead to successful business decisions, and the Delphi study final stage "weighing round" confirms the appropriate systematic structured instrument to develop workflow systems performance $[2,3,8]$.

Schmiedel et al. [4, 8] have completed a research study to identify BPM values and used them as validation of an instrument to measure an organisation's BPM system. This makes possible improved organisational process efficiency and effectiveness levels using Delphi's framework for decision-making improvement and innovation. Thus, the Delphi study has identified CERT values as BPM core values to achieve successful BPM, and allowed the construction of an instrumental procedure to measure and validate workflow information systems.

The Quyên [2] Delphi study has developed reliable and comprehensive key indicators to evaluate an organisation's governance practices. Five potential key indicators have been defined as dimensions of the organisation's practices. These five dimensions are (1) Management and Direction; (2) Participation; (3) Accountability; (4) Autonomy and Transparency; and (5) Management and Direction. The five dimensions identify resources at different levels within the organisation which are used for management purpose to realise the organisation's business tasks and duties. Thus, the Delphi method was very useful in identifying and measuring the five dimensions and in producing the initial key indicators of the weighting system.

A multi-criteria decision-making (MCDM) research study has been developed by Pangsri [10] using the Delphi method to make an MCDM tool for supporting experienced decision-makers in making several different and complex evaluations for construction projects. The research study used the Delphi method to evaluate alternatives and applied 'the order preference by similarity to ideal solution' (TOPSIS) weight technique to find the final decision-making criteria (Table 4). This resulted in the ranking of the projects. Thus, the use of the Delphi method along with other methods using the Delphi rounds can result in powerful decision tools for use in complex situations. Each of these published applications of the Delphi method is discussed in the following sections. 


\section{The Empirical Evidence of Delphi Studies}

The Delphi method has generated many empirical evidence in application to BPM, workflows, and information systems. Generally, empirical studies in this area of research should have a methodology which can be used to validate decision-making. In fact, the Delphi method in combination with BPM values can provide this as it confirms requirements and makes decisions based on Delphi's multiple round process (Table 1) using BPM values from the organisation's workflow systems. The Schmiedel et al. [4] Delphi study has implemented an evaluation of a measurement instrument designed to identify and evaluate four BPM key dimensional values, which can be used to ensure BPM objectives success (Table 3). This Delphi study has six stages to ensure the implementation of the BPM construct (BPMC) of CERT values, and how the CERT values concept is suitable for supporting decision-making by measuring BPM.

The Schmiedel et al. [4] Delphi study has two core strategic entities, which are the development core and validation core. The development core includes the study first stage for the items creation to identify the key indicators (dimensions) using a literature review, questionnaires, and interviews; the second stage for the substrata identification to identify the important items in order to construct categories; the third stage for the key items selection which come from item pools in stage two and ranking the items based on experts' responses; the fourth stage for indexing (key items revision) by conducting an index-card-sorting test, which is used to ask experts to identify key indicators from stage three and calculate the ratio of each indicator based on their feedback.

Overall, the identified key indicators from the development core entity are appropriately acceptable to be implemented in the validation core entity which includes: the fifth stage for the BPMC (instrument) preparation, which refines the identified indicators by developing a pre-test and a pilot test studies, and then a valid translation of the measurement BPMC (The pre-test study is used to evaluate and expand the understanding of the BPMC in such iterative process, while the pilot test

Table 3 The Schmiedel et al. [4] research study process

\begin{tabular}{|c|c|c|c|}
\hline Stage & BPMC development core & Stage & BPMC validation core \\
\hline 1 & $\begin{array}{l}\text { Items creation } \\
\text { Literature review } \\
\text { Questionnaires } \\
\text { Interviews }\end{array}$ & \multirow[t]{2}{*}{5} & \multirow[t]{2}{*}{$\begin{array}{l}\text { BPMC (Instrument) preparation } \\
\text { - Pre-test } \\
\text { - Pilot test } \\
\text { - BPMC validity and reliability } \\
\text { (Instrument translation) }\end{array}$} \\
\hline 2 & $\begin{array}{l}\text { Substrata identification } \\
\text { - Construct categories }\end{array}$ & & \\
\hline 3 & $\begin{array}{l}\text { Key items selection } \\
\text { - Ranking the indicators }\end{array}$ & \multirow[t]{2}{*}{6} & \multirow{2}{*}{$\begin{array}{l}\text { BPMC (Instrument) Application } \\
\text { - Factor analysis techniques } \\
\text { (field survey) }\end{array}$} \\
\hline 4 & $\begin{array}{l}\text { Indexing (key items revision) } \\
\text { - Index-card-sorting test }\end{array}$ & & \\
\hline
\end{tabular}


study has been conducted to evaluate and confirm the BPMC validity and reliability using an exploratory factor analysis.); the sixth stage for examining the application of the validated and reliable BPMC using confirmatory factor analysis techniques based on a field survey (questionnaire) to ensure the practicality of the CERT values instrument.

The Quyên [2] Delphi study collected results from four levels. The first level described an indicator set and constructs where ninety-one indicators were recognised. The second level was importance levels used to rank the importance of each indicator and the study found that all indicators should be included as $92.3 \%$ were rated very high (very important, or extremely important) and $7.7 \%$ rated relatively important. The third level examined consensus levels where three groups (A, B, C) were set to have the coefficient of quartile variation (CQV) along with interquartile range (IQR) and median levels to evaluate the convergence level within the experts' opinions as well as the indicators importance level. CQV was used to evaluate the consensus level within the ratings, and the $\mathrm{CQV}$ formula is $\mathrm{CQV}=(\mathrm{Q} 3-$ Q1)/(Q3 + Q1). The fourth level is the weighting system, which resulted from the indicators importance scores. The indicators mean scores are used to calculate the final indicator importance levels (indicator weights). An indicator weight is the ratio of an indicator importance score to the sum of all indicators importance scores within a factor. A factor weight is the ratio of the sum of all indicators importance scores within a factor to the sum of all indicators importance scores within a dimension. A dimension has a set of factors. In fact, the Quyên [2] study has recorded a high level of agreement in experts' opinions on the indicators importance of $70 \%$ indicating high reliability of the set. Also, the weighting results have shown significant differences in the indicator weights within $23 \%$ of the factor groups and in the dimensions' factor weights of $80 \%$. This indicates that the weighting is significant and confirms the results reliability.

\section{The Delphi Method Validity of Business Process Study Results}

The Delphi method has been chosen to develop business process studies because of Delphi's iterative measurement, which ensures the validity of the results [7]. In fact, Delphi's concentration on experts' responses has been found to be an appropriate approach for validating BPM decisions, key indicators, and important factors in several business studies [2, 10]. Hence, BPM and workflow systems studies need the Delphi method validity to ensure the flow of decisions throughout the business process.

The Pangsri [10] research study has used three decision-making methods (Fig. 1) as multi-criteria decision-making (MCDM) methodology for project management to successfully achieve specific objectives. The MCDM methodology consists of the Delphi method, the analytic hierarchy process (AHP) and technique for order preference by similarity to ideal solution (TOPSIS).

The analytic hierarchy process is a process for determining the weights of criteria to be used in complex decision situations. The AHP process consists of the 


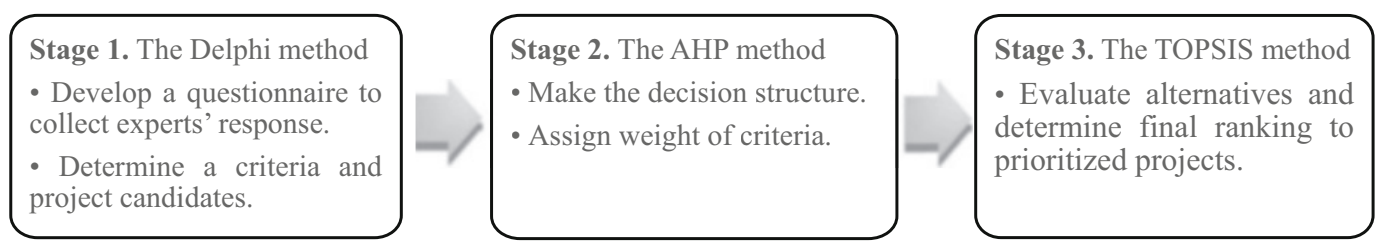

Fig. 1 MCDM research study methodology

following five steps: First, define the problem and develop the goal of the decision; Second, identify the decision structure (solution) based on the goal and develop the objectives; Third, develop a set of comparison matrices; for example, consider $n$ elements to be compared $C_{1}$ to $C_{n}$ then denote the relative significance weight of $C_{i}$ relating to $C_{j}$ by $a_{i j}$ and then form a square matrix $A=\left(a_{i j}\right)$ of order $n$ as $a_{i j}=1 / a_{j i}$ where $i \neq j$, and $a_{i i}=1$, all $i$; Fourth, the significance weight elements can be used to weigh the priorities for every element, then reweight the elements by adding its weighed values to have the overall global significance; Fifth, calculate the consistency index (CI) using formula $\lambda_{\max }-n /(n-1)$. The MCDM process will apply the AHP process in the assignment of weight of the criteria (Fig. 1).

The technique for order preference by similarity to ideal solution (TOPSIS) is a multi-criteria process for identifying solutions based on set of predetermined elements. The TOPSIS identifies a positive solution as criteria to maximise the benefits and/or minimises the cost. In contrast, a negative solution minimises the benefits and/or maximises the cost. TOPSIS process has five steps which are:

Step 1: Inputs the $x_{i j}$ for matrix of priorities as $i=1 \ldots m$ alternatives and $j=1 \ldots n$ criteria by $r_{i j}=\frac{x_{i j}}{\sqrt{\sum_{i=1}^{m} \sum_{j=1}^{n} x_{i j}^{2}}}$

Step 2: Use the weight normalised matrix

$$
v_{i j}=w_{i} r_{i j}, \text { where } i=1 \ldots m \text { and } j=1 \ldots n
$$

Step 3: Process the normalised decision matrix where the positive ideal solution $A^{+}$is identified by choosing the largest normalised and weighted score for each criterion, and the negative ideal solution $A^{-}$is identified by choosing the least normalised and weighted score of each criterion by the calculate of these formulas

$$
\begin{aligned}
& A^{+}=\left\{v_{1}^{+}, . ., v_{n}^{+}\right\}, \text {where } v_{j}^{+}=\left\{\max \left(v_{i j}\right) \in J \min \left(v_{i j}\right) \text { if } j \in J^{\prime}\right\} \\
& A^{-}=\left\{v_{1}^{-}, . ., v_{n}^{-}\right\}, \text {where } v_{j}^{*}=\left\{\min \left(v_{i j}\right) \in J \max \left(v_{i j}\right) \text { if } j \in J^{\prime}\right\}
\end{aligned}
$$


Table 4 The rank of the projects using TOPSIS

\begin{tabular}{l|l|l}
\hline Rank no. & Project ID & The project weight \\
\hline 1 & Project 5 & 0.747 \\
\hline 2 & Project 7 & 0.746 \\
\hline 3 & Project 3 & 0.614 \\
\hline 4 & Project 2 & 0.441 \\
\hline 5 & Project 4 & 0.386 \\
\hline 6 & Project 1 & 0.358 \\
\hline 7 & Project 6 & 0.264 \\
\hline
\end{tabular}

Step 4: Measure the positive and negative measures for each alternative using these formulas

$$
\begin{gathered}
S_{i}^{+}=\sqrt{\sum_{j=1}^{n}\left(v_{j}^{+}-v_{i j}\right)^{2}}, \\
S_{i}^{-}=\sqrt{\sum_{j=1}^{n}\left(v_{j}^{-}-v_{i j}\right)^{2}, i=1 \ldots m}
\end{gathered}
$$

Step 5: Obtain the relative closeness to the ideal solution (final weighting) by

$$
C_{i}^{+}=\frac{S_{i}^{-}}{\left(S_{i}^{-}+S_{i}^{+}\right)}, 0<C_{i}^{+}<1, i=1 \ldots m
$$

The implementation of the Pangsri [10] MCDM methodology has ranked the studied projects using TOPSIS at the final weighting to order the projects based on their importance and indexed values (Table 4).

\subsection{Delphi Results' Quality and Business Process Performance Development}

The quality of Delphi study results is high compared to other BPM study methods for evaluating and developing business process decisions and workflows [2, 4, 8]. The Delphi method's main advantage is in the reliability of the study results and the validation of the Delphi study findings as the experts' panel ensures this [4, 8]. In fact, several business studies have used Delphi's framework to develop key indicators and factors as Delphi study results have been confirmed to be appropriate in constructing complete weighted and validated indicators for evaluating business practices in such a systematic process [2]. Also, the Delphi method has been recognised as a structured communication exercise that allows the emergence of 
agreement in dealing with complex business issues in systematic way. The Delphi study method has the capability to identify the critical success factors (CSFs) necessary for achieving business objectives at the right level of performance [10].

The development of the business process workflow system and performance need an effective business study method to convert results to objectives in order to achieve the right business tasks at the right time with the right levels of quality and performance [14]. The results from Delphi's framework have demonstrated such effectiveness as Delphi studies have achieved the business objectives and enabled improvement in BPM systems for different organisations. Also, the Delphi method CSFs capability makes high levels of quality achievable, so business process performance can be developed to ensure the quality of business products and services throughout the workflow systems. The Delphi method's ability to identify and validate key indicators as a multi-dimensional construct for examining BPM can be used to explore empirically the relationship between BPM, workflow systems and business performance [4, 15]. Hence, the Delphi method and BPM values can play an important role in developing business process and workflow systems performance to achieve business objectives.

\section{Conclusion}

An information system needs a decision-making development framework to improve its business processes and workflow systems performance and the Delphi method can develop a workflow's decision-making framework. This paper has discussed three Delphi studies with different approaches to the use of the Delphi study technique to enhance business decision-making. Schmiedel et al. [4] has used the Delphi method to construct and validate business process management values, which can be used to ensure business workflow systems success. Quyên [2] has used the Delphi method to develop key indicators, importance and consensus levels, and a weighting system for measuring business practices to facilitate business processes. The Pangsri [10] multi-criteria decision-making study has developed a framework where the Delphi study technique has an important role in initiating the MCDM framework process and enabling the application of other decision-making techniques.

Together, the Delphi method and BPM values can be used to improve workflow framework and information systems performances by measuring BPM performance and identify the key indicators for enhancing business workflow information systems. Delphi study analysis and results have demonstrated several advantages where BPM performance success can be reached by applying the Delphi method. These advantages include the ability to:

- Identify key important business process indicators and/or factors.

- Recognise business performance using ranked keys. 
- Validate the BPM keys using Delphi's weighing system.

- Achieve business process performance success by implementing Delphi's BPMC.

In practice, the Delphi method has enhanced our ability to evaluate BPMC models and an organisation's workflow system in order to choose the right workflow mechanism that supports the organisation's services and productivity $[2,7]$.

To conclude, Delphi and BPM research studies have confirmed that Delphi's framework can be used to build a decision-making structure to develop an information system by improving the BPM and workflow system performance.

The research studies within the BPM framework, workflow decision-making, and workflow information systems development are still limited and there are many further opportunities and applications that could be explored. Hence, future use of the Delphi method to develop BPMC models and evaluate WIS performance is recommended as, to date, the Delphi method has demonstrated its ability to enhance business decision-making processes and systems.

\section{References}

1. N. Dalkey, O. Helmer, An experimental application of the Delphi method to the use of experts. Manag. Sci. 9(3), 458-467 (1963)

2. Đ. Quyên, Developing university governance indicators and their weighting system using a modified Delphi method. Procedia Soc. Behav. Sci. 141, 828-833 (2014)

3. J. Nworie, Using the Delphi technique in educational technology research. TechTrends 55(5), 24-30 (2011)

4. T. Schmiedel, J. vom Brocke, J. Recker, Development and validation of an instrument to measure organizational cultures' support of Business Process Management. Inf. Manag. 51(1), 43-56 (2014)

5. J. Becker, J. vom Brocke, M. Heddier, S. Seidel, In search of information systems (grand) challenges. Bus. Inf. Sys. Eng. 57(6), 377-390 (2015)

6. O. Thomas, J.A. vom Brocke, Value-driven approach to the design of service-oriented information systems-making use of conceptual models. IseB 8(1), 67-97 (2010)

7. A. Looy, M. Backer, G. Poels, Towards a Decision Tool for Choosing a Business Process Maturity Model, DESRIST 2012. LNCS, vol 7286 (Springer, Berlin Heidelberg, 2012), pp. 78-87

8. T. Schmiedel, J. vom Brocke, J. Recker, Which cultural values matter to business process management? Results from a global Delphi study. Bus. Process. Manag. J. 19(2), 292-317 (2013)

9. O. Müller, T. Schmiedel, E. Gorbacheva, J. vom Brocke, Toward a typology of business process management professionals: identifying patterns of competence through latent semantic analysis. Enterprise Inf. Sys. 10(1), 50-80 (2016)

10. P. Pangsri, Application of the multi criteria decision making methods for project selection. Univers. J. Manage. 3(1), 15-20 (2015)

11. C. Sonnenberg, J. vom Brocke, The missing link between BPM and accounting. Bus. Process. Manag. J. 20(2), 213-246 (2014)

12. J. vom Brocke, A. Simons, A. Cleven, Towards a business process-oriented approach to enterprise content management: the ECM-blueprinting framework. Inf. Sys. e-Bus. Manage. J. 9(4), 475-496 (2011) 
13. J. García, J. Vanderdonckt, C. Lemaige, J. Calleros, in How to Describe Workflow Information Systems to Support Business Process. 10th IEEE Conference on E-Commerce Technology and the Fifth IEEE Conference on Enterprise Computing, E-Commerce and E-Services (IEEE Computer Society, Washington DC, 2008), pp. 404-411

14. A. Draghici, A. Popescua, L. Gogan, A proposed model for monitoring organizational performance. Procedia Soc. Behav. Sci. 124, 544-551 (2014)

15. M. Kohlbacher, H. Reijers, The effects of process-oriented organizational design on firm performance. Bus. Process. Manag. J. 19(2), 245-262 (2013) 